\title{
Circadian chronotypes among wild-captured west Andean octodontids
}

\author{
ADRIÁN OCAMPO-GARCÉS ${ }^{1,2,3}$, WILSON MENA ${ }^{1}$, FELIPE HERNÁNDEZ ${ }^{3}$, \\ NELSON CORTÉS ${ }^{3}$ and ADRIÁN G PALACIOS ${ }^{1}$
}

\footnotetext{
${ }^{1}$ Centro de Neurociencias de Valparaíso, Universidad de Valparaíso, Valparaíso, Chile;

2 Departamento de Neurología y Neurocirugía, Hospital Clínico de la Universidad de Chile, Santiago, Chile;

${ }^{3}$ Programa de Fisiología y Biofísica, Instituto de Ciencias Biomédicas, Facultad de Medicina, Universidad de Chile, Santiago, Chile.
}

\begin{abstract}
Rest activity pattern was studied in wild-captured males of Octodon degus $(\mathrm{n}=9)$, Octodon bridgesi $(\mathrm{n}=3)$, and Spalacopus cyanus $(\mathrm{n}=6)$ (Rodentia: Octodontidae). Ten-minute resolution actograms were constructed from data obtained by an automated acquisition system. After two months of habituation to a stable light-dark schedule, recordings were performed in isolation chambers under a 12: 12 Light Dark schedule. A freerunning period (constant darkness) was recorded for O. bridgesi and S. cyanus. O. degus displayed a crepuscular pattern of rest activity rhythm. Entrained $O$. bridgesi and $S$. cyanus displayed nocturnal preference, with rest anticipating light phase and without crepuscular activity bouts. Under constant darkness, active phase occurred at subjective night in $O$. bridgesi and $S$. cyanus. Wild-captured $O$. bridgesi and $S$. cyanus possess a circadian driven nocturnal preference, while wild $O$. degus displays a crepuscular profile. Diurnal active phase preference of wild $S$. cyanus colonies observed in the field could not be explained solely by photic entrainment, since social and/or masking processes appear to be operative. The genus Octodon includes species with diverse chronotypes. We propose that crepuscular diurnal pattern observed in $O$. degus is a recent acquisition among the octodontid lineage.
\end{abstract}

Key terms: circadian rhythms, chronotype, Octodon, octodontids, Spalacopus cyanus.

\section{INTRODUCTION}

Several processes follow a 24-hour cycle determined by the photoperiod in the natural environment. The systematic and predictable changes in illumination, temperature and humidity create temporal niches in any ecosystem exposed to dawn and dusk. Timing mechanisms allow species inhabiting these ecosystems to adjust the temporal pattern of their behavior, synchronizing activity to these relatively ephemeral niches (Daan and Ascchoff, 1982). The timekeeping system that regulates behavior in the 24-hour time domain is the circadian system. The mammalian circadian system possesses a central oscillator located at the suprachiasmatic nucleus of the hypothalamus that generates a rhythm with a period close to 24 hours (van Esseveldt et al., 2000). Subjected to a stable 24-hour period light: dark cycle (photic zeitgeber), circadian rhythms maintain a stable phase relationship to dawn and dusk, a process called "entrainment" (Pittendrigh and Daan, 1976). Among the many overt rhythms modulated by the circadian system, a restactivity rhythm can be recognized. The restactivity rhythm is characterized by an Active Phase $(\alpha)$ and a Rest Phase $(\rho)$ (Moore-Ede et al., 1982). Under entrained conditions, $\alpha$ could occur mainly at light phase (diurnal chronotype) or at dark phase (nocturnal chronotype). In the absence of a photic zeitgeber, i.e., in constant light or

Corresponding author: Adrián Ocampo-Garcés, MD, PhD, Programa de Fisiología y Biofísica, Facultad de Medicina, Universidad de Chile, Casilla 70005, Correo 7, Santiago, Chile, Tel: (56-2) 978-6423, Fax: (56-2) 777-6916, E-mail: aocampo@med.uchile.cl 
darkness, the rest-activity rhythm free runs at the clock's endogenous period. The emergence of $\alpha$ in constant conditions delimits subjective day for diurnal chronotypes and subjective night for nocturnal chronotypes (Moore-Ede et al., 1982).

Current chronobiological and comparative physiological data show that mammalian species tend to cluster at some given chronotype depending on phylogenetic relationships, as occurs for the predominant nocturnal chiropterans and rodents, or for diurnal anthropoidean primates, suggesting that chronobiological attributes are acquired in the long-term phylogenetical history (Ahnelt and Kolb, 2000). The fact that some phase preference patterns predominate in a clade supports the notion that nocturnal to diurnal or diurnal to nocturnal shifts are exceptional processes (Smale et al., 2003). At a lower taxonomic level, there are few species with welldocumented circadian rest-activity rhythm that depart from their lineage's chronobiological pattern (de la Parra et al., 2003). By way of example, most species of the family sciuridae (squirrels) had been characterized as diurnal, as occurs with genera Ammospermophilus (Pohl 1983), Tamias (de Coursey et al., 2000), and Spermophilus (Martinet and Zucker, 1984) with the exception of species of the subfamily petauristinae (flying squirrels), such as the nocturnal Glaucomys (Refinetti, 1999). On the contrary, the diurnal genus Arvicanthis distinguishes from the nocturnal pattern predominant among murids (hamsters, rats and mice) (Duplantier and Granjon, 1990).

Here, we present the case of three species of two closely related genera of the family octodontidae (Rodentia: Hystricognatha). The family octodontidae is endemic to South America and comprises ten species distributed in six genera (Honeycutt et al., 2003). Current evidences suggest that octodontidae include noctunal and crepuscular species, particularly among species of monophiletic genus Octodon. Early field reports described $O$. degus as a diurnal-active species (Fulk, 1976), and specimens of $O$. degus obtained in captive colonies have been described as diurnalcrepuscular under controlled conditions (Labyak et al., 1997; Garcia-Allegue et al., 1999). Field data reported that O. lunatus is predated by nocturnal carnivora (MuñozPedreros, 2000), and O. bridgesi is trapped almost exclusively during night hours (Muñoz and Murúa, 1987). Individuals of the social and fossorial octodontid Spalacopus cyanus have been described as diurnal according to field reports (Rezende et al., 2003; Urrejola et al., 2005). Specimens obtained in captive-bred colonies exhibit nocturnal preference for activity when recorded in isolation chambers (Begall et al., 2002). To further clarify the phase preference of activity among wild-living colonies, we studied the rest-activity cycle of wild-captured individuals of $S$. cyanus, $O$. degus, and $O$. bridgesi entrained to a 12: 12 light: dark schedule.

\section{METHODS}

All individuals recorded were males captured in their natural environment. Nine O. degus (165-230 grs), six S. cyanus (110195 grs), and three O. bridgesi (180-210 grs) were captured by means of baited medium-sized Sherman traps (Octodon species) or padded leg-hold traps ( $S$. cyanus). After at least a two-month period of adaptation to captivity conditions under a stable 12: 12 light: dark cycle, the animals were installed in recording cages $(30 \mathrm{x} 40 \mathrm{x}$ $30 \mathrm{~cm}$ ) contained in individual isolation chambers $(65 \times 60 \times 60 \mathrm{~cm})$. Light intensity was set at 300 lux during light hours. A red light of less than 10 luxes allowed the housekeeping of animals under constant darkness. Ambient temperature was maintained at $21-23^{\circ} \mathrm{C}$, with food and water ad libitum. One week of adaptation to recording environment was left before data acquisition.

Recording started with an entrainment period (12: 12 light dark schedule) of at least 10 days. Afterwards, two of the species (O. bridgesi 3 subjects, S. cyanus 6 subjects) were further assessed under constant darkness for at least three weeks after the end of the entrainment period. 
An automated computer-based acquisition system designed for long-term sleep-wake recording was adapted to record rest activity rhythm (Vivaldi et al. 1994). The system recorded and stored, originally in 15-second epochs, the activity counts detected by a piezoelectric device placed at the base of the animal's cage. Activity counts were later collapsed into ten-minute epochs (144 per day).

\section{Data analysis}

To describe rest activity pattern under entrained conditions, the following parameters were obtained: onset of $\alpha$, onset of $\rho$, time span of $\alpha$, fraction of $\alpha$ occurring during the light phase, fraction of total activity counts that occur during the light phase, and the acrophase and the nadir of the rest-activity cycle. Time was expressed as Zeitgeber Time (ZT), with lights-on at ZT 0 and lights-off at ZT 12. Time profile of activity was assessed at ten-minute resolution. Individual values for each parameter were estimated from the mean activity counts for each ten-minute epoch, across all recording days. A 12-hour (72 ten-minute epochs) moving average was applied to the mean activity counts to obtain the acrophase and the time of the nadir. The beginning and the end of $\alpha$ were estimated individually with the help of an activity threshold. The threshold of activity corresponded to the 24-hour average of cumulated activity counts obtained during the recording period for each animal (see figures 1,2 and 3). The $\alpha$ onset was set at the first epoch of the first sustained upward crossing of the activity threshold (three consecutive ten-minute epochs above threshold) occurring after the activity nadir. The $\rho$ onset was set at the first epoch of the first sustained downward crossing of the activity threshold (three consecutive tenminute epochs under threshold) occurring after the acrophase of activity. Given the strong bimodal pattern observed among most $O$. degus, an additional criterion was necessary to assess onset and offset of $\alpha$ based on a 6-hour backward moving average. For degus, $\alpha$ onset occurred whenever a sustained upward crossing of activity threshold: (i) followed the nadir of activity and (ii) preceded the steepest and longest interval of positive slope of the 6hour backward moving average. The $\rho$ onset occurred whenever a sustained downward crossing of activity threshold: (i) followed the acrophase of activity and (ii) preceded the steepest and longest interval of negative slope of the 6-hour backward moving average.

Phase preference of activity (chronotype) under entrained conditions was estimated for each animal. The chronotype was defined as diurnal or nocturnal if all of the following three requisites occurred at the light or dark phase respectively: (i) the acrophase of activity; (ii) presence of more than a half of time span of $\alpha$; and (iii) presence of more than a half of activity counts (assessed by light to dark paired t-test for individual pooled days). An intermediate chronotype was assigned to individuals falling outside the defined criteria. Under free-running conditions, raster plots of activity were double plotted to assess $\alpha$ and $\rho$ by visual inspection.

To assess the null hypothesis of equal light-dark distribution activity counts under 12: 12 LD condition, a two-tailed paired ttest was applied to the pooled experimental days of each animal. One-way ANOVA for factor specie $(O$. degus, O. bridgesi and $S$. cyanus) and unpaired student tests were applied to compare intraspecific differences for descriptive parameters under entrained conditions.

\section{RESULTS}

Activity counts obtained during one week of recording and their corresponding means are presented in Figures 1 to 3 . Figure 1 helps to visualize the particular crepuscular pattern exhibited by most $O$. degus specimens. Because of the extreme bimodal profile, a six-hour moving average was necessary to differentiate a downward crossing that precede the rest phase from the downward crossing that precedes the crepuscular dip in activity occurring at the middle of active phase (Fig. 1). Figures 2 


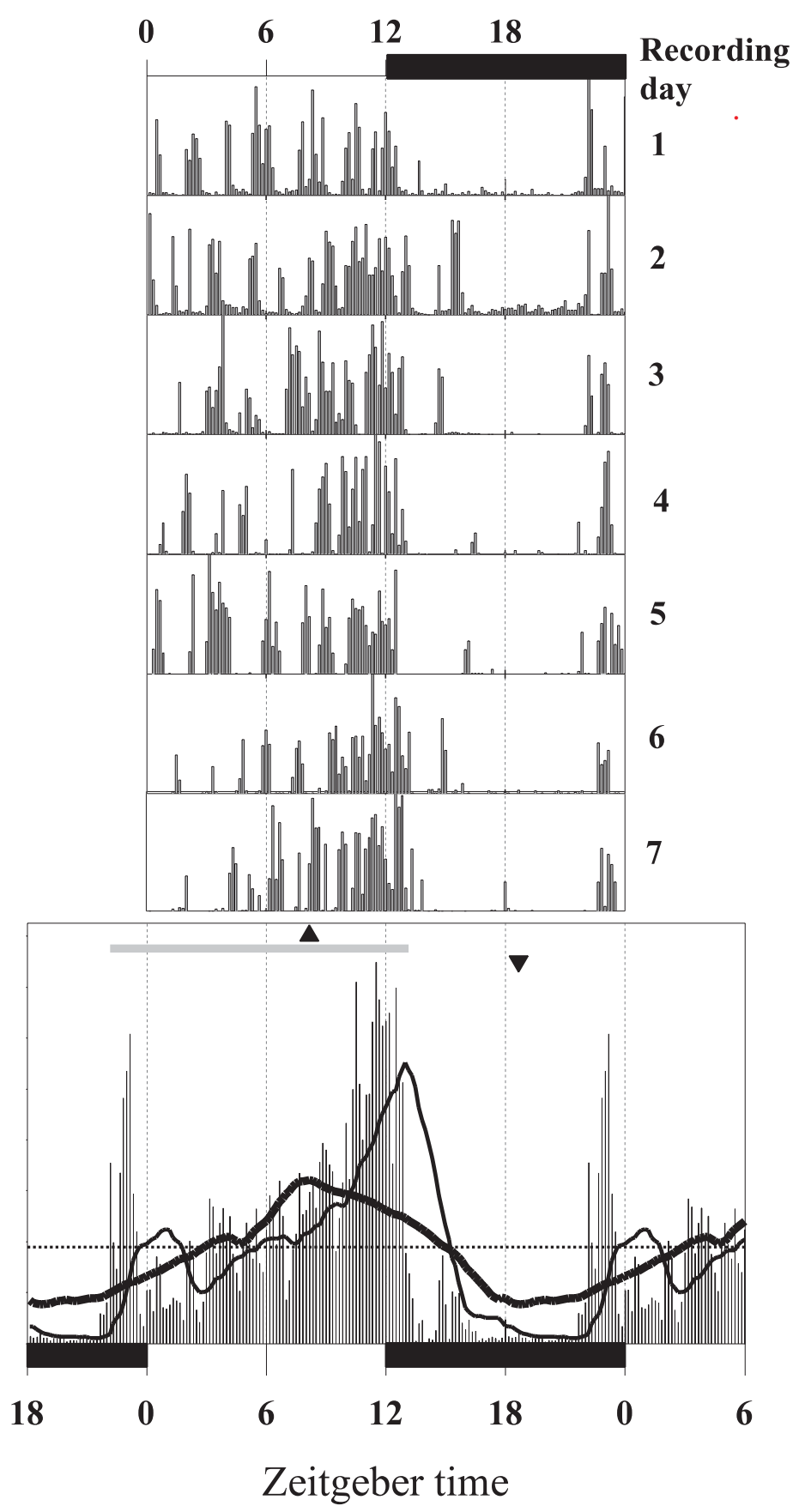

Figure 1: Rest-activity pattern of $O$. degus. Ten-minute resolution actogram for seven consecutive days of recording (top), and mean activity counts obtained during the recording period (bottom) of a diurnal Octodon degus. Chronotype of each individual is obtained by (i) an activity threshold (dotted line), (ii) a 12-hour (72 ten-minute epochs) moving average of cumulated activity (thick solid curve) whose maxima correspond to activity acrophase (triangle-up) and minima to nadir (triangle-down), and for degus (iii) a 6-hour (36 ten-minute epochs) backward-moving average (thin solid curve). Onset and offset of active phase (gray horizontal line) is delimited by upward and downward crossings of cumulated activity on activity threshold, associated to the steepest positive and negative slope intervals of the 6-hour backward-moving average, respectively. Time is represented in hours after lights-on (Zeitgeber time). Dark phase is indicated by horizontal filled bar at abcissa. 

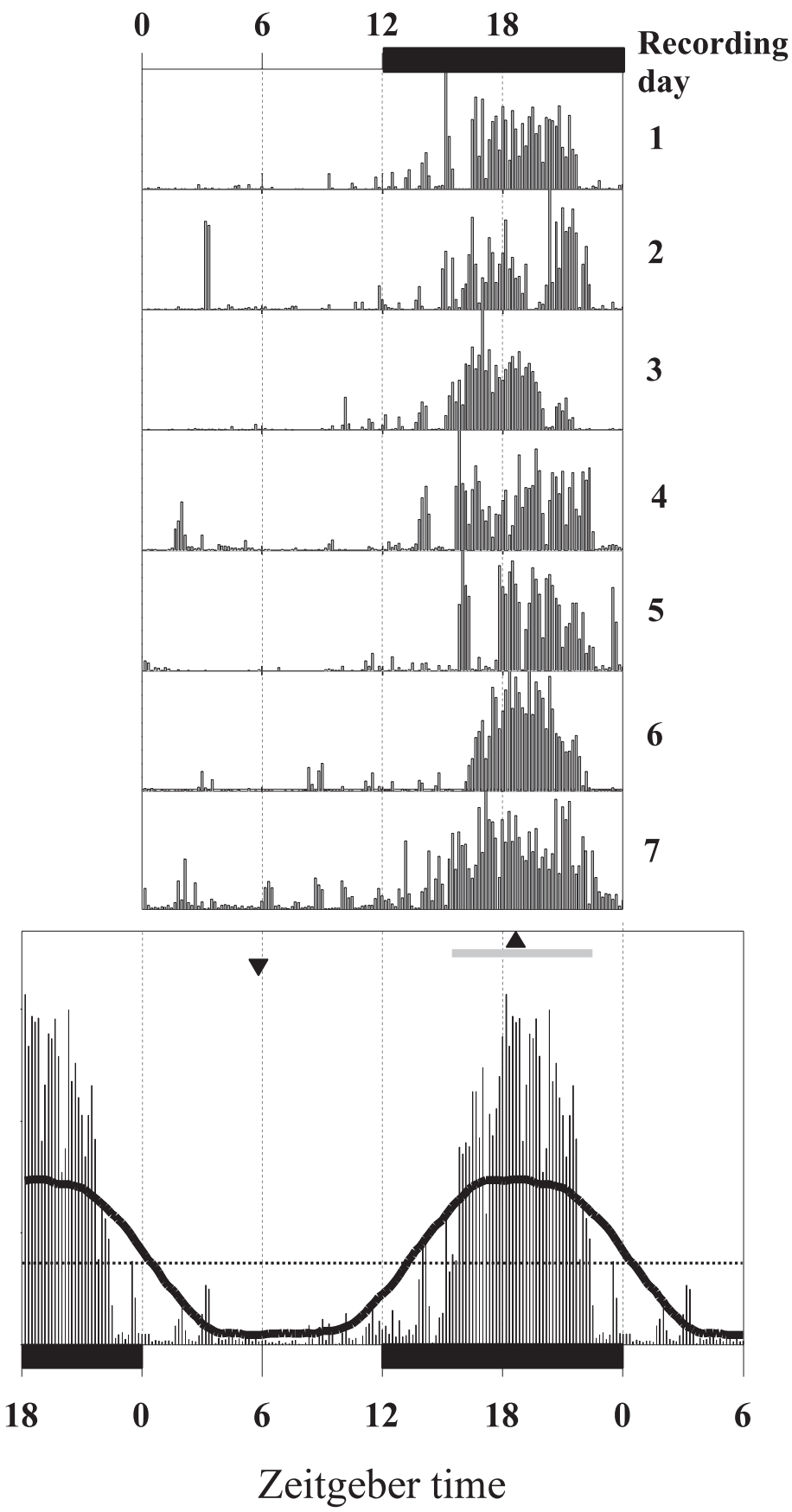

Figure 2: Rest-activity pattern of $O$. bridgesi. One-week actogram (top) and cumulated activity counts obtained during recording period (bottom) of a representative individual. Symbols as in Figure 1.

and 3 depict a typical rest-activity profile obtained in wild $O$. bridgesi and S. cyanus respectively.

Figure 4 presents summary data for the three species under entrained conditions. Most of $O$. degus specimens concentrated their activity during light hours (see Table I for details). The activity phase started around the early morning and extended to the early night hours. The acrophase was located in the second half of light phase in close association with the evening peak of 
activity. O. degus individuals exhibit a prominent bimodal pattern associated to dawn and dusk transitions, corresponding to a morning and evening peak of activity respectively. This bimodal pattern remained almost stable across recording periods. $O$. bridgesi and $S$. cyanus invariably displayed a strict night preference for activity. $O$. bridgesi individuals started the activity phase at around one hour after lights-off and finished one hour before lights-on, and nadir and acrophase of activity were located near noon and midnight hours respectively.
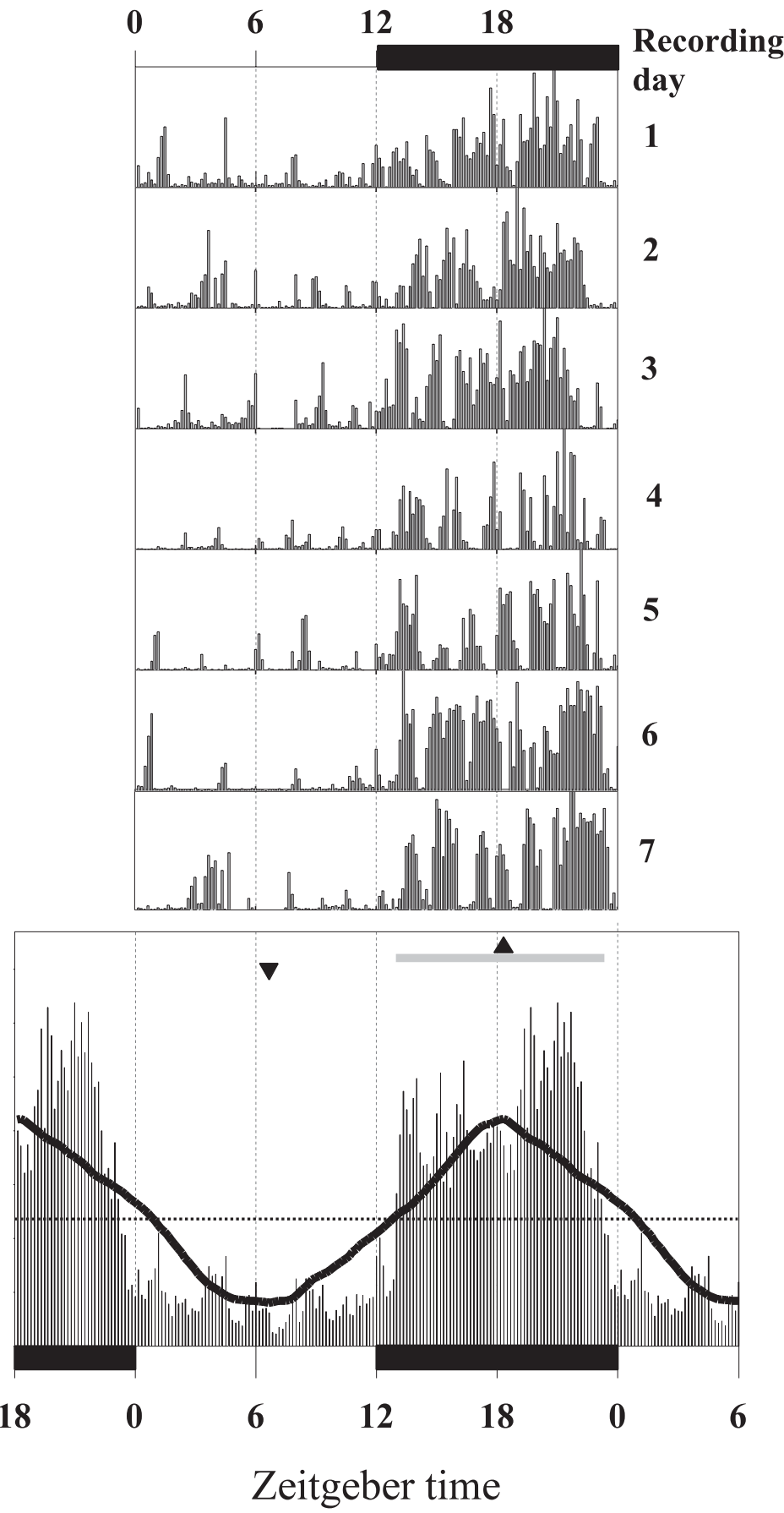

Figure 3: Rest-activity pattern of Spalacopus cyanus. One-week actogram (top) and cumulated activity counts obtained during recording period (bottom) of a representative animal. Symbols as in Figure 1. 


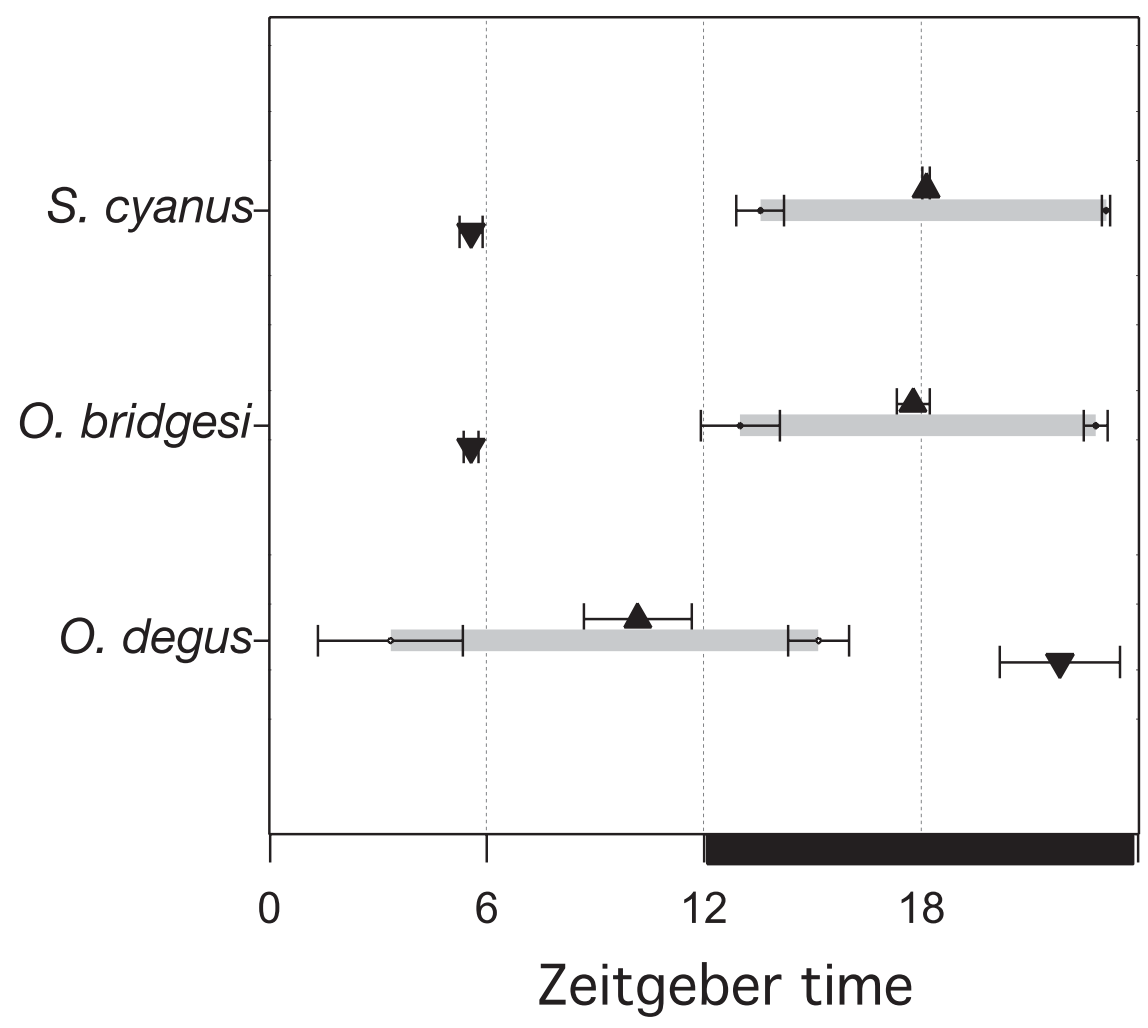

Figure 4: Active phase (gray horizontal line), acrophase (triangle-up) and nadir (triangle-down) of the studied species. Values of each parameter (mean and SEM) correspond to that presented in Table I.

Table I summarizes phase preference parameters for the three species. The whole pool of $O$. bridgesi and S. cyanus displayed a robust nocturnal preference for activity, concentrating $99 \%$ and $100 \%$ of their active phase, and $96 \%$ and $87 \%$ of their activity counts in the dark hours respectively. For the three $O$. bridgesi and six $S$. cyanus, the dayversus-night paired t-test were highly significant $(\mathrm{p}<0.001)$. No significant differences were detected for any of the studied parameters among $O$. bridgesi and $S$. cyanus. When all subjects of each species were pooled, $O$. degus differed from $O$. bridgesi and from $S$. cyanus in all descriptive parameters, with the only exception of $\alpha$ duration. It was observed that four degus consistently concentrated activity counts during the light phase (paired t-test, $\mathrm{p}<0.05)$ and two during the dark phase (paired t-test, $\mathrm{p}<0.05$ ). The complementary parameters (acrophase and fraction of $\alpha>50 \%$ ) concurred to define them as diurnal and nocturnal chronotypes, respectively. Two other $O$. degus were diurnal according to the acrophase and fraction of active phase, but the activity count distribution was not different between the light and dark phases. Finally, one degus concentrated $\alpha$ and displayed the acrophase during the dark phase, but the activity counts were equally distributed during dark and light phases. Day-to-day variability in the percentages of activity counts occurring during light phase measured as standard error of the mean ranged from 2.3 to $3.6 \%$, from 1.4 to $3.3 \%$, and from 2.0 to $5.2 \%$ for diurnal, nocturnal and intermediate individuals.

Figure 5 depicts the emergence of a circadian rest-activity rhythm under constant darkness for one representative case of $O$. bridgesi and $S$. cyanus. In that condition, $\alpha$-free runs with $\alpha$-onset located at the predicted dusk. In the pool of $O$. bridgesi and $S$. cyanus recorded under constant conditions, a sustained restactivity rhythm was evident during the whole recording period that allowed for an unequivocal definition of subjective night based on a occurrence. Visual inspection of 
double plots obtained under constant darkness demonstrates an endogenous period shorter than 24 hours among $O$. bridgesi. The pool of $S$. cyanus exhibit higher inter-individual variability for endogenous period length under constant darkness, being shorter than 24 hours in two cases, longer than 24 hours in other two, and almost close to 24 hours among the remaining two specimens.

TABLE I

Summary statistics for active-phase (mean and standard error). Acrophase, Nadir, onset of active phase and rest phase in Zeitgeber Time. Duration of active phase in hours. Activity counts during light phase in percentage of cumulated total. Chronotype definition explained in Methods. "Parameters in which $O$. degus is different from O. bridgesi and $S$. cyanus (two-tailed unpaired t-test $\mathrm{p}<0.05$ ). \& Pearson Chi-square value of $3 \times 3$ contingency table for chronotype distribution among species is $11.45(\mathrm{p}=0.02)$

\begin{tabular}{lcccc}
\hline & O.degus & O. bridgesi & S. cyanus & ANOVA for \\
$\mathrm{N}$ & 9 & 3 & 6 & $\begin{array}{c}\text { Factor Specie } \\
\mathrm{F}(\mathrm{p})\end{array}$ \\
\hline Acrophase & $10.1(1.4) \#$ & $17.8(0.5)$ & $18.1(0.1)$ & $13.8(<0.01)$ \\
Nadir & $21.9(1.7) \#$ & $5.6(0.2)$ & $5.6(0.3)$ & $45.2(<0.01)$ \\
$\alpha$ onset & $3.3(2.0) \#$ & $13.0(1.1)$ & $13.6(0.7)$ & $10.9(<0.01)$ \\
$\rho$ onset & $15.2(0.8) \#$ & $22.8(0.3)$ & $23.1(0.1)$ & $42.4(<0.01)$ \\
$\alpha$ duration & $11.8(1.4)$ & $9.8(1.3)$ & $9.6(0.7)$ & $0.9(>0.05)$ \\
Activity counts during light phase & $52.9(6.9) \#$ & $7.5(1.5)$ & $12.8(3.5)$ & $15.8(<0.01)$ \\
Percentage of $\alpha$ during light phase & $61.0(12.6) \#$ & $1.0(1.0)$ & 0 & $10.8(<0.01)$ \\
Chronotype & & & & \\
Nocturnal & 2 & 3 & - & \\
Diurnal & 4 & - & - & \\
Intermediate & 3 & - & & \\
\hline
\end{tabular}

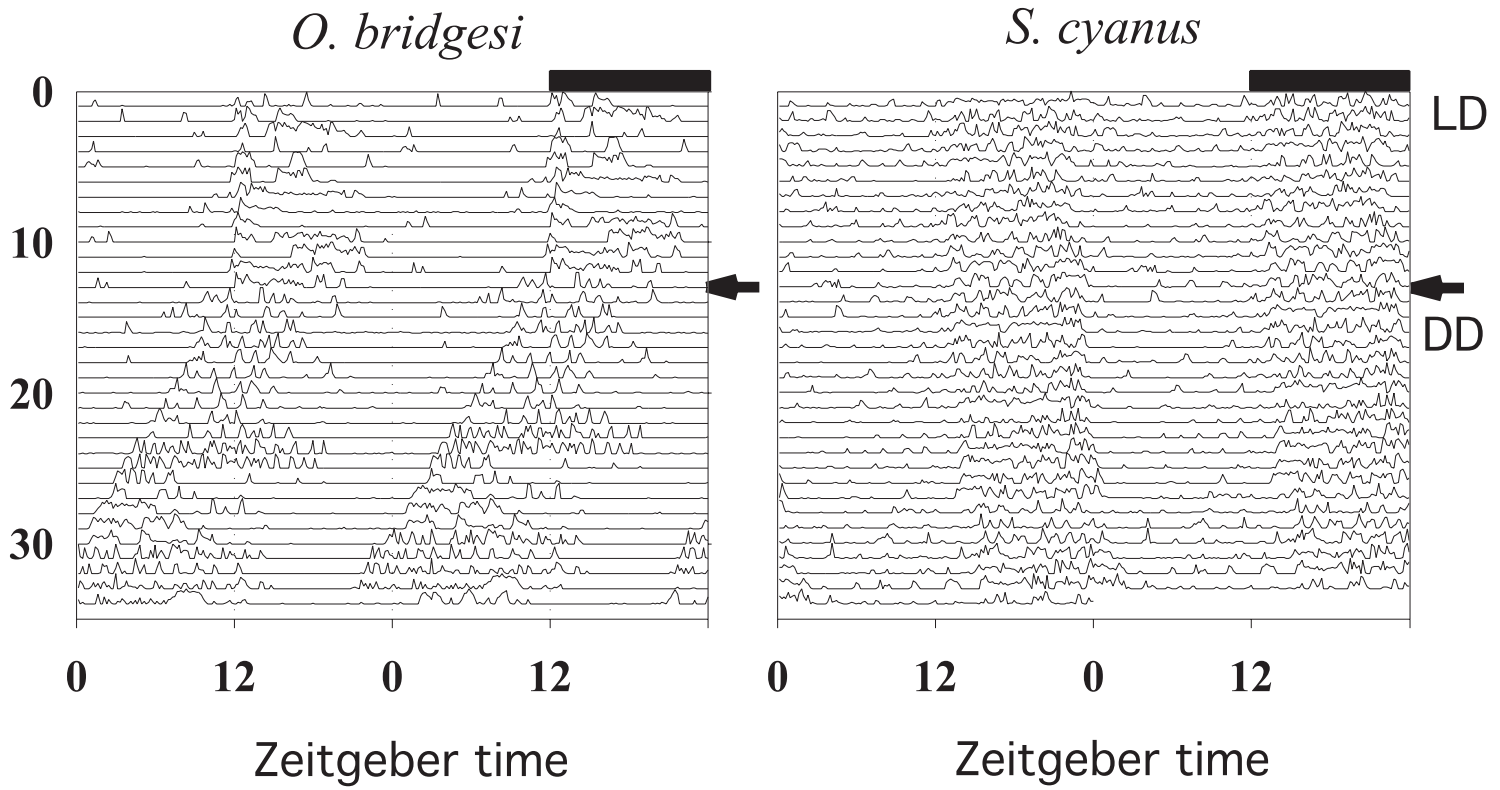

Figure 5: Double-plotted actograms obtained under entrained (LD) and free-running conditions (DD) in representative cases of $O$. bridgesi (left) and $S$. cyanus (right). Beginning of free running at day 14 is indicated by an arrow. 


\section{DISCUSSION}

The main goal of our work was to characterize under controlled conditions the rest-activity patterns of wild-captured individuals of three octodontid species. When entrained to a 12: 12 light: dark schedule in isolation chambers, $O$. bridges $i$ and $S$. cyanus displayed nocturnal phase preference without crepuscular bouts, while $O$. degus always exhibited a crepuscular pattern. The nocturnal chronotype of $O$. bridgesi and $S$. cyanus was further confirmed by the sustained rest-activity rhythm that emerged at the predicted time of dusk under free-running conditions.

This report explored, for the first time, the temporal profile of activity of $O$. bridgesi. This herbivorous specie inhabits forested biota of the western and part of the eastern slope of the Andes Mountains between latitudes $34^{\circ}$ and $40^{\circ}$ south (Verzi and Alcover, 1990; Muñoz-Pedreros, 2000). No solid information is currently available to establish the nature of social or other ethological dimensions in $O$. bridgesi (Ebensperger, 1998). Some data suggest that, in contrast to O.degus, O. bridgesi is a poor digger and that part of his activity, such as feeding or nesting, could occur in the top of the forest (Muñoz and Murúa, 1987). The specie plagues timber plantations of the forest industry (Muñoz and Murúa, 1987; Muñoz-Pedreros et al., 1990). The gradual destruction of his natural habitat and the extensive use of pesticides in timber plantations render the conservation status of $O$. bridgesi as vulnerable (Muñoz and Murúa, 1989; Muñoz-Pedreros, 2000). As far as we know, $O$. bridgesi has not been bred in captivity, a fact that makes it difficult to obtain large numbers of specimens for experimental studies. Our characterization of the chronobiology of $O$. bridgesi is consistent with a nocturnal chronotype, where $\alpha$ starts one hour after dusk and $\rho$ anticipates dawn by about one hour. O. bridgesi individuals displayed a stable, free-running period of the rest-activity rhythm, with a period shorter than 24 hours. The emergence of $\alpha$ at the expected dusk under free-running conditions supports the notion that $\alpha$ delimits the subjective night. The former results are in keeping with field reports documenting the nocturnal timing of captures (Muñoz and Murúa, 1987; Verzi and Alcover, 1990).

$S$. cyanus is a social and fossorial specie (Ebensperger, 1998). S. cyanus colonies inhabit the semi-arid environment of central Chile. The colonies build complex systems of underground galleries. Burrow systems were estimated to be up to $600 \mathrm{~m}$ long, ran at a depth of $15 \mathrm{~cm}$, and had a diameter of $6 \mathrm{~cm}$ (Begall and Gallardo, 2000). Occasionally, individuals emerge during the light phase to monitor the vicinity or forage (Rezende et al., 2003). A recent study performed in $S$. cyanus bred in captivity reported that isolated $S$. cyanus and family groups displayed a consistent nocturnal preference (Begall et al., 2002). Surprisingly, in contrast to the expected re-entrainment observed in isolated individuals, family groups did not entrain to a phase shift of the photic zeitgeber, suggesting that social living somehow interferes with photic entrainment in S. cyanus. Social entrainment has been demonstrated to occur in other rodents, including the closely related $O$. degus (Goel and Lee, 1995). It could be hypothesized that the galleries of $S$. cyanus are distant enough from the surface to impede or to make photic entrainment irrelevant for their fossorial mode of life. Field data obtained by visual inspection of wild colonies show consistently that $S$. cyanus forages above ground exclusively during daytime hours (Rezende et al., 2003). The timing of above-ground activity during light phase exhibits seasonal fluctuations, peaking at midday during winter and displaying a bimodal-crepuscular pattern during summer. The temporal distribution of activity observed in the field suggests that photic entrainment is operating in wildliving colonies of $S$. cyanus, where the specie seems to have diurnal phase preference for activity. A recent radiotelemetric study performed in wild colonies living in their natural environment also supports the presence of a diurnal active phase (Urrejola et al., 2004). In a recent report, we described that $S$. cyanus rod density in retina is lower than that of 
nocturnal surface-dwelling rodents and that an unexpectedly high $10 \%$ proportion of the photoreceptors are cones (Peichl et al., 2005). The high cone proportion suggests adaptation to diurnal surface visual demands, rather than to the lightless subterranean environment. One possible explanation for the conflicting field versus laboratory results could be that $S$. cyanus bred in captivity (Begall et al., 2002) exhibit a modified restactivity rhythm with respect to their wild cospecifics. Rezende and coworkers (2003) studied the rest-activity pattern in wildcaptured individuals maintained in artificial galleries and subjected to a 12: 12 LD schedule. Under entrained conditions isolated $S$. cyanus concentrated locomotor activity during the dark phase. Our chronobiological characterization of $S$. cyanus confirmed a nocturnal chronotype for wild-captured individuals, with $\alpha$ starting about two hours after dusk and $\rho$ anticipating dawn by approximately one hour under entrained conditions. Furthermore, a clear rest-activity pattern was evidenced in actograms obtained under free running in the six individuals studied, with $\alpha$-onset predicting the time of dusk. The free-running rhythm remains stable during the recording period, with period lengths that varied among individuals. The former result makes the masking effect of light an improbable explanation for the observed pattern of $S$. cyanus under entrained conditions. The diurnal phase preference of wild-living $S$. cyanus colonies could be an emergent property determined by a combination of a weak photic zeitgeber and strong social entrainment. It has been hypothesized for fossorial bathyerigids that social processes could explain, in part, diurnal phase preference (Oosthuizen et al., 2003). Our results in isolated, wild-captured $S$. cyanus open interesting questions on the role of social or other unknown zeitgebers and/or masking processes operating in natural environments for this gregarious fossorial specie. Further research is needed to explain the timing of activity observed in wild-living $S$. cyanus colonies.

$O$. degus is found in semiarid habitats on the western slope of the Andean mountains between $28^{\circ}$ and $35^{\circ}$ south latitude (Woods and Boraker, 1975). O. degus display complex social strategies associated with burrowing (Ebensperger, 1998) and foraging (Vasquez, 1997). A recent report documented the seasonal rest-activity patterns of above-ground activity in wild colonies of the specie (Kenagy et al., 2002). Based on visual observations, a diurnalcrepuscular pattern becomes evident during summer and a unimodal noon-centered one during winter. The chronobiology of $O$. degus has been described in captive-bred colonies. Some results obtained in captive degus are relevant for chronobiology because they exhibit multiple chronotypes in captive-bred colonies (Labyak et al., 1997; García-Allegue et al., 1999; Kas and Edgar, 2000). Intraspecific diversity of chronotypes is a phenomenon rarely described in the literature for living species other than humans (Horne and Östberg, 1976). One of the goals of our study was to explore whether wild-captured $O$. degus exhibit a diurnal pattern like the one observed in their natural habitat. Four out of nine individuals exhibit diurnal preference, while two displayed a prominent nocturnal preference with more than $70 \%$ of activity counts concentrated in the evening bout of activity that occurred almost entirely during the dark phase (data not shown). The diurnal preference described in field reports is contradicted by individuals displaying nocturnal preference under controlled conditions, as also has been described by Kas and Edgar in captive-bred degus (1999, 2000). This result suggests that wild populations share with captive-bred colonies the existence of multiple chronotypes. Unfortunately, current field reports are based on populational descriptions, precluding chronotype evaluation in the field, as has been done for other species with suspected multiple chronotype expression (Blanchong et al., 1999). A crepuscular pattern was evident among our wild degus. Crepuscular rather than diurnal profile also result evident for captive-bred $O$. degus in sleep recordings (Kas and Edgar, 1998). We are currently extending our recordings in wild-captured individuals to further characterize chronotypes among wild populations of $O$. degus. 


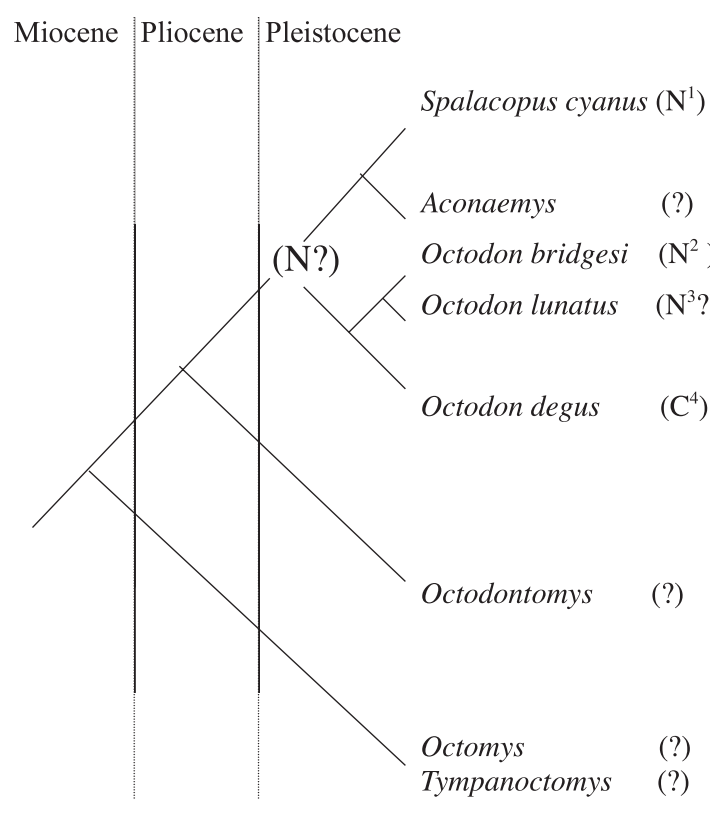

Figure 6: Phylogenetic relationships and timing of evolution among octodontid family, as proposed by Honeycutt et al. (2003). West Andean octodontids radiated during Pleistocene in three genera. Current chronobiological evidences (1. Begall et al., 2002; Rezende et al., 2003; Ocampo-Garcés, present report; 2. Ocampo-Garcés, present report; 3. OcampoGarcés et al., 2003; 4. Labyak et al., 1997; García-Allegue et al., 1999; Kas and Edgar, 2000) support the notion that nocturnalism (N) is present among two of them. We propose that the ancestral chronotype of the lineage was nocturnal and that crepuscular-diurnal (C) pattern is a recent acquisition of the octodontid lineage. A question mark (?) indicates preliminary or no chronobiological information for that taxon.

Present results and preliminary data in the northern $O$. lunatus obtained under entrained and free-running conditions (OcampoGarcés et al., 2003) suggest that at least two of the three living species of the monophyletic Octodon genus (Honeycutt et al., 2003) display nocturnal preference of activity, in contrast to the crepuscular $O$. degus. When contrasting chronobiological information with current knowledge on phylogenetic relationships among genera of family octodontidae (Honeycutt et al., 2003), it could be proposed that the crepuscular diurnal pattern is a recent acquisition in the octodontid lineage (Fig 6). Genus Octodon would be unique among rodents in that it includes species that have been documented as differing in rest-activity patterns (de la Parra et al., 2003). In conclusion, the family octodontidae represent a taxon of interest for studying the mechanisms that determine phase preferences of overt circadian rhythms.

\section{ACKNOWLEDGEMENTS}

Thanks are due to Drs. Rodrigo Vásquez and Bárbara Saavedra in providing wildcaptured $O$. bridgesi specimens. Drs. Francisco Bozinovic and Luis Ebensperger graciously provided specimens of $S$. cyanus, and Dr. Claudia Cecchi helped us in capturing wild $O$. degus specimens. We thank Juan Peirano for providing technical support in data acquisition, Dr. Ennio Vivaldi for helpful comments on this manuscript and Mr. Cristián López for excellent animal care. Research supported by FONDECYT Grant 3010028. The experiments undertaken in this study are in agreement with Chilean regulations on animal research.

\section{REFERENCES}

AHNELT PK, KOLB H (2000) The mammalian photoreceptor mosaic-adaptative design. Prog Retin Eye Res 19: 711-777

BEGALL S, GALLARDO MH (2000) Spalacopus cyanus (Rodentia: Octodontidae): an extremist in tunnel constructing and food storing among subterranean mammals. J Zoology 251: 53-60

BEGALL S, DAAN S, BURDA H, OVERKAMP GJ (2002) Activity patterns in a subterranean social rodent, Spalacopus cyanus (OCTODONTIDAE). J Mammal 83: $153-158$

BLANCHONG JA, MCELHINNY TL, MAHONEY MM, SMALE L (1999) Nocturnal and diurnal rhythms in the unstriped Nile Rat, Arvicanthis niloticus. J Biol Rhythms 14: 364-377

DAAN S, ASCHOFF J (1982) Circadian contribution to survival. In: ASCHOFF J, DAAN S, GROOS G (eds) Vertebrate Circadian Systems. New York: SpringerVerlag, Berlin Heidelberg. pp: 305-321

DE COURSEY PJ, WALKER JK, SMITH SA (2000) A circadian pacemaker in free-living chipmunks: Essential for survival? J Comp Physiol A 186: 169-180

DE LA PARRA J, JADUE C, VIVALDI EA (2003) Phylogeny and nocturnal-diurnal transitions in rodents. Biol Res 36: R-67 
DUPLANTIER JM, GRANJON L (1990) Rythmes d'activitè chez six espèces du muridès du Sénégal appartenant aux genres Mastomys, Arvicanthis, Myomys and Dasymys. Mammalia 54: 173-182

EBENSPERGER L (1998) Sociality in rodents: The new world fossorial hystricognaths as study model. Rev Chil Hist Nat 71: 65-77

FULK GW (1976) Notes on the activity, reproduction, and social behavior of Octodon degus. J Mammal 57: 495505

GARCÍA-ALLEGUE R, LAX P, MADARIAGA AM, MADRID JA (1999) Locomotor and feeding activity rhythms in a light-entrained diurnal rodent, Octododon degus. Am J Physiol 277: R523-531

GOEL N, LEE TM (1995) Sex differences and effects of social cues on daily rhythms following phase advances in Octodon degus. Physiol Behav 58: 205-213

HONEYCUTT RL, ROWE DL, GALLARDO MH (2003) Molecular systematics of the South American caviomorph rodents: Relationships among species and genera in the family Octodontidae. Mol Phylogenet Evol 26: 476-489

HORNE JA, ÖSTBERG O (1976) A self-assessment questionnaire to determine morningness-eveningness in human circadian rhythms. Int J Chronobiol 4: 97-110

KAS MJ, EDGAR D (1998) Crepuscular rhythms of EEG sleep-wake in a hystricomorph rodent, Octodon degus. J Biol Rhythms 13: 9-17

KAS MJ, EDGAR D (1999) A nonphotic stimulus inverts the diurnal-nocturnal phase preference in Octodon degus. J Neurosci 19: 328-33

KAS MJ, EDGAR D (2000) Photic phase response curve in Octodon degus: Assessment as a function of activity phase preference. A J Physiol 278: R1385-1389

KENAGY GJ, NESPOLO RF, VÁSQUEZ RA, BOZINOVIC F (2002) Daily and seasonal limits of time and temperature to activity of degus. Rev Chil Hist Nat 75: 567-581

LABYAK SE, LEE TM, GOEL N (1997) Rhythm chronotypes in a diurnal rodent, Octodon degus. Am J Physiol 273: R1058-R1066

MARTINET L, ZUCKER I (1984) Role of the pineal gland in circadian organization of diurnal ground squirrels. Physiol Behav 34: 799-803

MOORE-EDE MC, SULZMAN FM, FULLER CA (1982) The Clock That Times Us. London: Harvard University Press

MUÑOZ A, MURÚA R (1987) Biología de Octodon bridgesi bridgesi (Rodentia, Octodontidae) en la zona costera de Chile central. Boletín de la Sociedad de Biología de Concepción (Chile) 58: 107-117

MUÑOZ A, MURÚA R (1989) Efectos de la reforestación con Pinus radiata sobre la diversidad y abundancia de los micromamíferos en un agroecosistema de Chile central. Turrialba 39: 143-150

MUÑOZ-PEDREROS A, MURÚA R, GONZÁLEZ L (1990) Ecological niche of small mammals in a forest agroecosystem of central Chile. Rev Chil Hist Nat 63 : 267-277

MUÑOZ-PEDREROS A (2000) Orden rodentia. In: MUÑOZ-PEDREROS A, YÁÑEZ J (eds) Mamíferos de Chile. Valdivia: CEA Ediciones

OCAMPO-GARCÉS A, VALLADARES JP, PALACIOS AG (2003) Octodon lunatus: A nocturnal octodontid of northern Chile. Sleep 26: A117

OOSTHUIZEN MK, COOPER H, BENNET N (2003) Circadian rhythms of locomotor activity in solitary and social species of African mole-rats (Family: Bathyerigidae) J Biol Rhythms 18: 481-490

PEICHL L, CHÁVEZ AE, OCAMPO-GARCÉS A, MENA W, BOZINOVIC F, PALACIOS AG (2005) Eye and vision in the subterranean rodent Cururo (Spalacopus Cyanus, Octodontidae). J Comp Neurol 486: 197-208

PITTENDRIGH CS, DAAN S (1976) A functional analysis of circadian pacemakers in nocturnal rodents. VI. Entrainment: Pacemaker as a clock. J Comp Physiol A 106: 291-331

POHL H (1983) Light pulses entrain the circadian activity rhythm of a diurnal rodent (Ammospermophilus leucurus) Comp Biochem Physiol 76B: 723-729

REFINETTI R (1999) Relationship between the daily rhythms of locomotor activity and body temperature in eight mammalian species. Am J Physiol 277: R1493R1500

REZENDE EL, CORTÉS A, BACIGALUPE LD NESPOLO RF, BOZINOVIC F (2003) Ambient temperature limits above-ground activity of the subterranean rodent Spalacopus cyanus. J Arid Environ 55: $63-74$

ROENNEBERG T, DAAN S, MERROW M (2003) The art of entrainment. J Biol Rhytms 18: 183-194

SMALE L, LEE T, NÚNEZ AA (2003) Mammalian diurnality: Some facts and gaps. J Biol Rhythms 18: 356-366

URREJOLA D, LACEY EA, WIECZOREK JR, EBENSPERGER LA (2005) Daily activity patterns of free-living cururos (Spalacopus cyanus). J Mammal 86: 302-308

VAN ESSEVELDT LE, LEHMAN MN, BOER GJ (2000) The suprachiasmatic nucleus and the circadian timekeeping system revisited Brain Res Rev 33: 34-77

VÁSQUEZ RA (1997) Vigilance and social foraging in Octodon degus (Rodentia: Octodontidae) in central Chile. Rev Chil Hist Nat 70: 557-563

VERZI DH, ALCOVER A (1990) Octodon bridgesi, Waterhouse 1844 (Rodentia: Octodontidae) in the Argentinian living mammalian fauna. Mammalia 54: 61-67

VIVALDI EA, WYNEKEN U, RONCAGLIOLO M, OCAMPO-GARCÉS A, ZAPATA A (1994) Measures of location and dispersion of sleep state distributions within the circular frame of a 12: 12 light: dark schedule in the rat. Sleep 17: 208-219

WOODS CA, BORAKER DK (1975) Octodon degus. Mamm Species 67: 1-5 